\title{
PROMOSI KESEHATAN TENTANG KELUARGA BERENCANA PADA WANITA USIA SUBUR SEBAGAI UPAYA AWAL UNTUK MEWUJUDKAN KELUARGA BERKUALITAS
}

\author{
Eny Retna Ambarwati ${ }^{1}$ dan Isabela Rahmawati ${ }^{2}$ \\ ${ }^{1}$ Prodi Kebidanan Sekolah Tinggi Ilmu Kesehatan AKBIDYO \\ Email: enyretna@gmail.com \\ ${ }^{2}$ Prodi Kebidanan Sekolah Tinggi Ilmu Kesehatan AKBIDYO \\ Email: isabellarahmawati15@gmail.com
}

\begin{abstract}
Goverment plans programmes to prevent preagnant postpone with family planning programme. Family planning programme for forming small family with socio economic power by childbirth control to gets happy and prosperous family to fulfill his life needs. General problems are family planning. Based on data they are interpreted that contraseptive users are still low. Low use of contraseption caused by many factors, one of them is knowledge of society about contraception. Counseling is one kind of methods for increase knowledge. Counseling is done on january 31 st, 2009 at pendopo, hamlet of guwosari village, subdistric pajangan, distric bantul. Number of women of childbearing ange and follow conseling as many as 20 womwn of childbearing age. Before conseling has been done, partisipant were given pretes to see knowledge level of fertile womwn then conseling was conducted with lecture and discussion. Conseling used compilation powerpoint. Media and lifted about various types of contraseptions. After conseling has been done then post test to see increased knowledge fertile women about material that has been given. Pre test value $76.67 \%$ and after consuled. Then post test value of fertile women increase to be $86.67 \%$, increase $10 \%$.
\end{abstract}

Keyword: Health Promotion, Family Planning, Mature Womans

\begin{abstract}
ABSTRAK
Pemerintah mencanangkan program untuk mencegah dan menunda kehamilan dengan melaksanakan program KB. Program KB yaitu untuk membentuk keluarga kecil sesuai dengan kekuatan sosial ekonomi suatu keluarga dengan cara pengaturan kelahiran anak agar diperoleh suatu keluarga bahagia dan sejahtera yang dapat memenuhi kebutuhan hidupnya. Permasalahan yang dihadapi secara umum adalah permasalahan Keluarga Berencana. Berdasarkan data yang telah diperoleh dapat diinterprestasikan bahwa pengguna kontrasepsi masih rendah. Rendahnya penggunaan kontrasepsi disebabkan oleh berbagai faktor, salah satunya adalah tingkat pengetahuan. Kurangnya pengetahuan tentang alat kontrasepsi KB. Berdasarkan permasalahan tersebut, solusi yang ditawarkan adalah melakukan promosi kesehatan melalui penyuluhan tentang keluarga berencana pada wanita usia subur diharapkan akan meningkatkan pengetahuan masyarakat tentang alat kontrasepsi. Penyuluhan merupakan salah satu cara untuk meningkatkan pengetahuan. Penyuluhan dilakukan pada tanggal 31 Januari 2019 di Pendopo RT 05 Dusun Dukuh Desa Guwosari Kecamatan Pajangan Kabupaten Bantul. Jumlah wanita usia subur yang datang dan mengikuti penyuluhan sebanyak 20 wanita usia subur. Sebelum dilakukan penyuluhan, peserta diberikan pretest untuk melihat tingkat pengetahuan wanita usia subur kemudian dilakukan penyuluhan dengan metode ceramah dan diskusi. Penyuluhan menggunakan media powerpoint penyuluhan dan liflet tentang berbagai macam alat kontrasepsi.Setelah selesai dilakukan penyuluhan kemudian dilakukan postest untuk melihat peningkatan pengetahun wanita usia subur terhadap materi yang telah diberikan. nilai pretest sebesar 76,67\% dan setelah dilakukan penyuluhan, kemudian dilakukan posttest, dapat dilihat bahwa nilai posttest wanita usia subur meningkat menjadi 86,67\%. Terjadi peningkatan sebesar $10 \%$.
\end{abstract}

Kata kunci: Promosi Kesehatan, Keluarga Berencana, Wanita Usia Subur

\section{PENDAHULUAN}

Keluarga berencana merupakan usaha untuk mengukur jumlah anak dan jarak kelahiran anak yang diinginkan. Maka dari itu, Pemerintah mencanangkan program atau cara untuk mencegah dan menunda kehamilan. Tujuan dilaksanakan program KB yaitu untuk membentuk keluarga kecil sesuai dengan kekuatan sosial ekonomi suatu keluarga dengan cara pengaturan kelahiran anak 
agar diperoleh suatu keluarga bahagia dan sejahtera yang dapat memenuhi kebutuhan hidupnya (Sulistyawati, 2013). Program Keluarga Berencana (KB) dapat mengurangi faktor risiko kehamilannya dalam 4T yaitu terlalu muda, terlalu tua, terlalu dekat dan terlalu jauh yang juga merupakan faktor terjadinya kematian ibu. Drop out peserta KB di indonesia masih cukup tinggi. Tingkat putus pakai tertinggi adalah pil $41 \%$, kondom $31 \%$, dan suntik $25 \%$. Tingkat drop out pasien yang menggunakan kontrasepsi jangka pendek jenis hormonal seperti, pil, suntik terus mengalami peningkatan pil 38,8\%, kondom 38,3\%, suntik 23\%, IUD 9,9\%, implant 5,7\% selanjutnya menjadi pil 41\%, kondom 31\%, suntik 25\%, IUD 6\%, dam implant $8 \%$ (Mufdlilah and Aryekti, 2016). Faktor yang mempengaruhi drop out KB salah satunya adalah pengetahuan. Pengetahuan tentang jenis kontrasepsi, keuntungan serta kerugian dalam menggunakan alat kontrasepsi mempengaruhi seorang ibu untuk menggunakan alat kontrasepsi. Besarnya angka kejadian putus pakai, kegagalan cara/alat, atau ganti cara/alat dapat dipakai sebagai petunjuk bahwa diperlukan perbaikan dalam pemberian bimbingan tentang pemilihan alat/cara kontrasepsi, pelayanan lanjutan dan penyediaan pelayanan yang lebih luas, sehingga sebagian besar ibu lebih memilih menggunakan kontrasepsi alami.

Dusun Dukuh merupakan sebuah pedukuhan di desa Guwosari Kecamatan Pajangan Kabupaten Bantul. Dusun Dukuh terletak di pinggiran ibukota kabupaten Bantul, dengan luas area kurang lebih 41 Ha. Sebelah utara berbatasan dengan Gandekan, sebelah timur dengan kelurahan Bantul, sebelah selatan dengan Ringinharjo dan sebelah barat dengan Kentolan Kidul (http://wikimapia.org/). Data dari Dinas Kesehatan dan survei keluarga di Dusun Dukuh bahwa permasalahan yang dihadapi secara umum adalah permasalahan Keluarga Berencana. Berdasarkan data yang telah diperoleh dapat diinterprestasikan bahwa pengguna kontrasepsi masih rendah. Rendahnya penggunaan kontrasepsi disebabkan oleh berbagai faktor, salah satunya adalah tingkat pengetahuan. Kurangnya pengetahuan tentang alat kontrasepsi yang meliputi macam macam alat kontrasepsi, pengertian, keuntungan, efek samping, waktu yang tepat untuk pemasangan. Berdasarkan permasalahan tersebut, solusi yang ditawarkan adalah melakukan promosi kesehatan tentang keluarga berencana pada wanita usia subur diharapkan akan meningkatkan pengetahuan masyarakat tentang alat kontrasepsi mengenai pengertian, efek samping, keuntungan, dan waktu yang tepat untuk pemasangan.

\section{TINJAUAN PUSTAKA}

a. Promosi Kesehatan

Promosi kesehatan adalah upaya untuk meningkatkan kemampuan masyarakat melalui pembelajaran dari, oleh, untuk dan bersama masyarakat, agar mereka dapat menolong diri sendiri, serta mengembangkan kegiatan yang bersumber daya masyarakat, sesuai sosial budaya setempat dan didukung kebijakan publik yang berwawasan kesehatan.

b. Keluarga Berencana

1) Definisi

Keluarga Berencana (KB) adalah suatu program yang dicanangkan pemerintah dalam upaya peningkatan kepedulian dan peran serta masyarakat melalui pendewasaan usia perkawinan (PUP), pengaturan kelahiran, pembinaan ketahanan keluarga, peningkatan kesejahteraan keluarga kecil, bahagia dan sejahtera (Hanafi, 2010).

2) Macam-Macam Kontrasepsi

Macam-macam alat kontrasepsi yang ada dan dapat digunakan oleh masyarakat dalam program KB antara lain metode kontrasepsi sederhana, metode kontrasepsi hormonal, AKDR, kontrasepsi mantab. Semua alat kontrasepsi tersebut, semuanya memiliki keunggulan masingmasing (Syaifudin, 2003).

a) Metode Kontrasepsi Sederhana 
Metode kontrasepsi sederhana terdiri dari 2 yaitu metode kontrasepsi sederhana tanpa alat dan metode kontrasepsi dengan alat. Metode kontrasepsi tanpa alat antara lain: Metode Amenorhoe Laktasi (MAL), Couitus Interuptus, Metode Kalender, Metode Lendir Serviks, Metode Suhu Basal Badan, dan Simptotermal yaitu perpaduan antara suhu basal dan lendir servik. Sedangkan metode kontrasepsi sederhana dengan alat yaitu kondom, diafragma, cup serviks dan spermisida (Handayani, 2010).

b) Metode Kontrasepsi Hormonal

Metode kontrasepsi hormonal pada dasarnya dibagi menjadi 2 yaitu kombinasi (mengandung hormon progesteron dan estrogen sintetik) dan yang hanya berisi progesteron saja. Kontrasepsi hormonal kombinasi terdapat pada pil dan suntikan/injeksi. Sedangkan kontrasepsi hormon yang berisi progesteron terdapat pada pil, suntik dan implant (Handayani, 2010).

c) Metode Kontrasepsi dengan Alat Kontrasepsi Dalam Rahim (AKDR)

Metode kontrasepsi ini secara garis besar dibagi menjadi 2 yaitu AKDR yang mengandung hormon sintetik (sintetik progesteron) dan yang tidak mengandung hormon (Handayani, 2010). AKDR yang mengandung hormon Progesterone atau Leuonorgestrel yaitu Progestasert (Alza-T dengan daya kerja 1 tahun, LNG-20 mengandung Leuonorgestrel.

d) Metode Kontrasepsi Mantap

Metode kontrasepsi mantap terdiri dari 2 macam yaitu Metode Operatif Wanita (MOW) dan Metode Operatif Pria (MOP). MOW sering dikenal dengan tubektomi karena prinsip metode ini adalah memotong atau mengikat saluran tuba/tuba falopii sehingga mencegah pertemuan antara ovum dan sperma. Sedangkan MOP sering dikenal dengan nama vasektomi, vasektomi yaitu memotong atau mengikat saluran vas deferens sehingga cairan sperma tidak dapat keluar atau ejakulasi (Handayani, 2010).

\section{METODE PENERAPAN IPTEKS}

Berikut ini metode penerapan IPTEKS yang digunakan dalam PKM seperti pada Gambar 1.

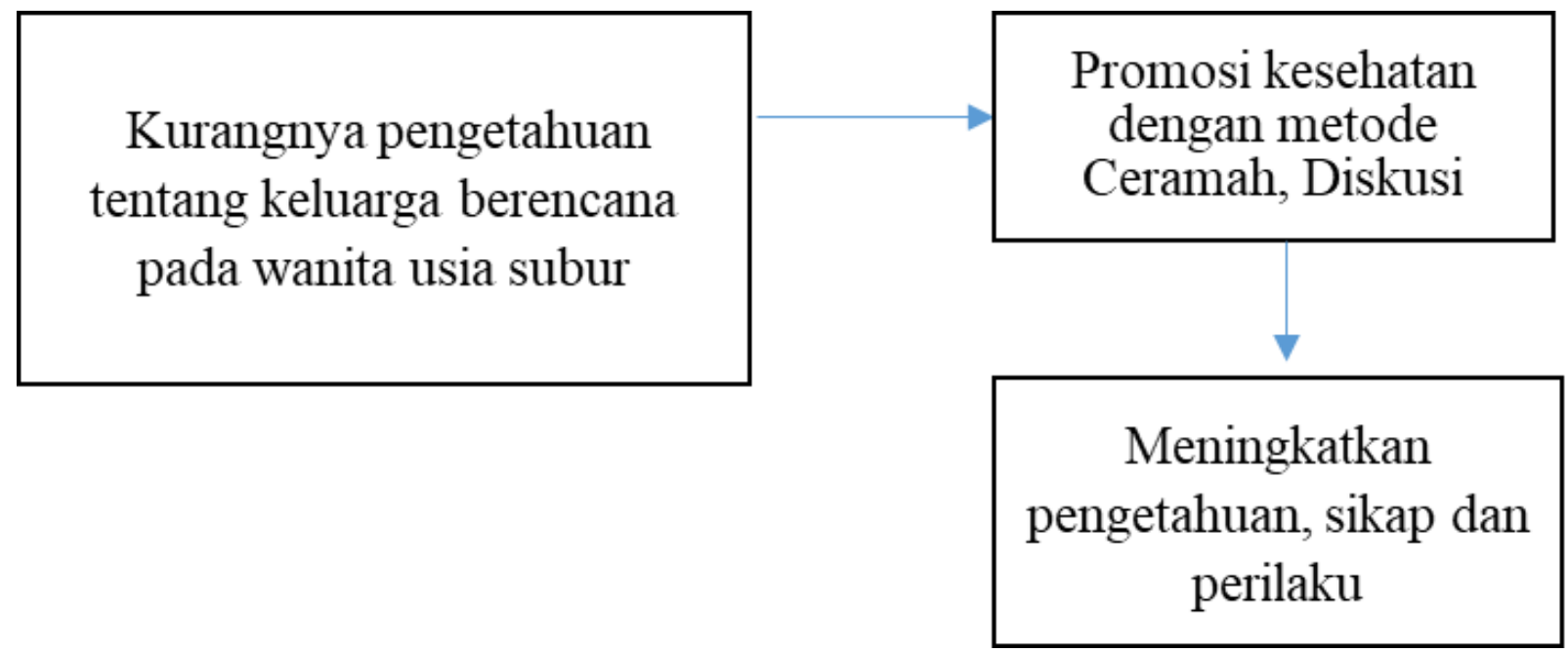

Gambar 1. Metode Penerapan IPTEKS 
Pengabdian kepada masyarakat bertujuan untuk meningkatkan pengetahuan, sikap dan perilaku masyarakat melalui penyuluhan tentang alat kotrasepsi KB meliputi pengertian, efek samping, keuntungan, dan waktu yang tepat untuk pemasangan. Penyuluhan tentang alat kontrasepsi dilakukan di Dusun Dukuh Desa Guwosari Pajangan Bantul.

Pada pelaksanaan kegiatan PKM ini, langkah pertama, melakukan pengkajian dengan survey awal ke Dinas Kesehatan Kabupaten Bantul, Kelurahan Pajangan dan Kepala Dusun Dukuh. Berdasarkan survey tersebut didapatkan beberapa permasalahan yang dihadapi. Langkah kedua, menyiapkan materi kegiatan PKM. Langkah ketiga melakukan penyuluhan tentang alat kotrasepsi KB meliputi pengertian, efek samping, keuntungan, dan waktu yang tepat untuk pemasangan. Tim pengabdian membuat kuisioner penilaian dengan memberikan pretest dan posttest, pelaksanaan penyuluhan. Evaluasi dilakukan untuk mengetahui sejauh mana efektivitas program ini untuk mencapai tujuan kegiatan yang telah dicanangkan. Adapun aspek yang dievaluasi meliputi : efektvitas pelaksanaan dilihat dari : manfaat kegiatan, tingkat pengetahuan dan pemahaman. Perubahan tingkat pengetahuan dilihat dari nilai pre dan pos test.

\section{HASIL PENGABDIAN}

Tim Pengabdian Kepada Masyarakat telah dilakukan pengabdian pada Hari Kamis tanggal 31 Januari 2019, pukul 09.00 WIB., bertempat di Pendopo RT 05 Dusun Dukuh Desa Guwosari Kecamatan Pajangan Kabupaten Bantul. Jumlah wanita usia subur yang datang dan mengikuti penyuluhan sebanyak 20 wanita usia subur.

Sebelum dilakukan penyuluhan, peserta diberikan pretest untuk melihat tingkat pengetahuan wanita usia subur penyuluhan tentang alat kotrasepsi KB meliputi pengertian, efek samping, keuntungan, dan waktu yang tepat untuk pemasangan. Kemudian dilakukan penyuluhan dengan metode ceramah dan diskusi. Penyuluhan menggunakan media powerpoint penyuluhan dan liflet tentang bebragai macam alat kontrasepsi.Setelah selesai dilakukan penyuluhan kemudian dilakukan postest untuk melihat peningkatan pengetahun wanita usia subur terhadap materi yang telah diberikan. Hasil perbandingan nilai pretest dan posttest dapat dilihat pada Gambar 2.

\section{Series 1}

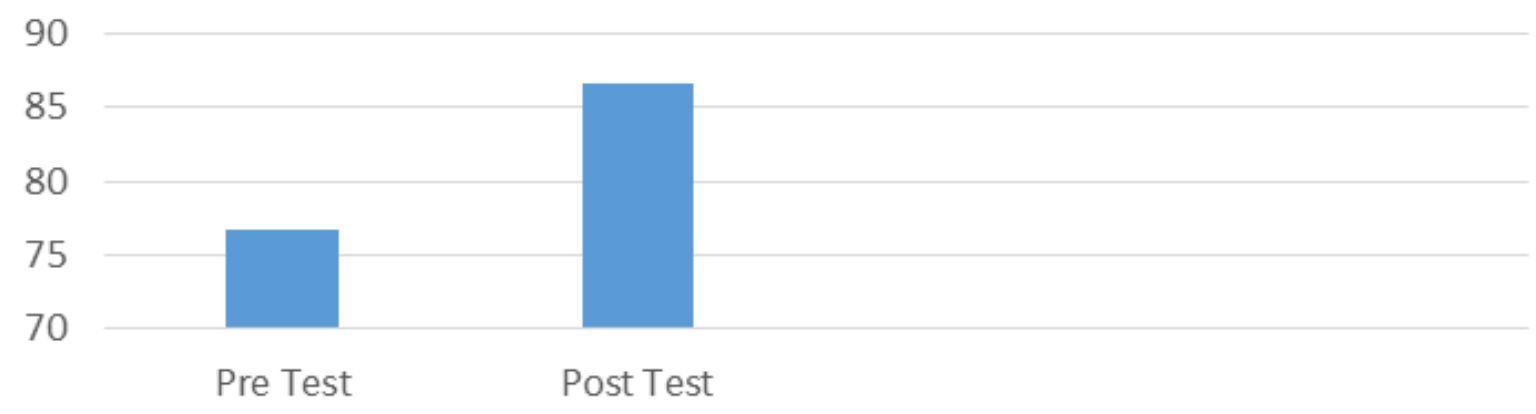

Series 1

Gambar 2. Hasil Perbandingan Nilai Pretest dan Posttest 
Dari Gambar 2 dapat dilihat bahwa nilai pretest sebesar 76,67\% dan setelah dilakukan penyuluhan, kemudian dilakukan posttest, dapat dilihat bahwa nilai posttest wanita usia subur meningkat menjadi $86,67 \%$. Terjadi peningkatan sebesar $10 \%$.

\section{DISKUSI}

Tingkat pengetahuan wanita usia subur meningkat setelah diberikan penyuluhan berupa materi alat kontrasepsi KB. Pemberian penyuluhan ini meningkatkan pemahaman dan pengertian wanita usia subur tentang hal-hal yang berkaitan dengan alat kotrasepsi KB meliputi pengertian, efek samping, keuntungan, dan waktu yang tepat untuk pemasangan. Pengetahuan merupakan hasil "tahu" dan terjadi setelah seseorang mengadakan penginderaan terhadap suatu obyek tertentu. Pengetahuan atau kognitif merupakan domain yang sangat penting untuk terbentuknya tindakan seseorang, yaitu termasuk partisipasi dalam suatu kegiatan (Notoatmodjo, 2012). Salah satu hal yang mempengaruhi pengetahuan adalah informasi, kemudahan untuk memperoleh informasi membantu mempercepat sesorang memperoleh pengetahuan yang baru (Mubarak, 2011). Informasi dapat diberikan melalui penyuluhan.

Penyuluhan merupakan serangkaian kegiatan komunikasi dengan menggunakan media dalam memberikan bantuan terhadap pengembangan potensi, yaitu fisik, emosi, sosial, sikap dan pengetahuan semaksimal mungkin sebagai upaya untuk meningkatkan atau memelihara kesehatan (Notoadmojo, 2010). Penyuluhan tentang alat kontrasepsi diberikan kepada Wanita Usia Subur sebagai upaya meningkatkan pengetahuan wanita subur tentang alat kontrasepsi meliputi pengertian kontrasepsi, macam-macam alat kontrasepsi, indikasi dan kontraindikasi masingmasing alat kontrasepsi, efek samping alat kontrasepsi dan penggunaan alat kontrasepsi. Tujuan yang ingin dicapai dari penyuluhan tentang alat kontrasepsi ini adalah meningkatkan pengetahuan para wanita usia subur tentang alat kontrasepsi sehingga diharapkan dapat menerapkan pengetahuan yang telah didapatkan tersebut dalam perilaku hidup sehat, yaitu dengan memiliki sikap untuk memilih dan menggunakan alat kontrasepsi sesuai dengan keadaan dirinya. Tujuan penyuluhan tentang alat kontrasepsi ini sesuai dengan tujuan utama dari penyuluhan secara umum yaitu untuk peningkatan pengetahuan atau sikap masyarakat, peningkatan perilaku masyarakat, dan peningkatan status kesehatan masyarakat (Nursalam, 2009).

Terjadi perubahan pengetahuan sebelum diberikan penyuluhan dibandingkan dengan setelah diberikan penyuluhan. Minat wanita usia subur untuk memahami isi penyuluhan juga sangat besar, sehingga penyuluhan tentang alat kontrasepsi KB tersebut mudah diterima wanita usia subur. Menurut WHO salah satu usaha atau strategi yang dapat dilakukan untuk memperoleh perubahan perilaku tersebut adalah dengan cara pemberian penyuluhan (WHO, 2010). Pemberian informasi dalam bentuk penyuluhan merupakan suatu proses yang bermanfaat untuk menciptakan iklim atau kondisi yang mempengaruhi perilaku individu.

Berdasarkan penelitian sebelumnya tentang pengaruh penyuluhan kesehatan terhadap pengetahuan Wanita Usia Subur (WUS) dalam pemilihan kontrasepsi di Desa Kalama Darat Kecamatan Tamako Kepulauan Sangihe yang yang dilakukan oleh Kaseuntung, dkk (2015) didapatkan hasil bahwa nilai $\mathrm{p}=0,000$ sehingga ada pengaruh penyuluhan kesehatan terhadap pengetahuan wanita usia subur dalam pemilihan alat kontrasepsi.

Pengetahuan seseorang dipengaruhi pendidikan. Orang yang berpendidikan tinggi akan memberikan respon yang lebih rasional terhadap informasi yang datang dan akan berpikir sejauh mana keuntungan yang akan mereka dapatkan (Notoatmodjo, 2007). Wanita usia subur dalam penelitian ini sebagian besar berpendidikan menengah dinilai mempunyai tingkat pendidikan yang cukup tinggi sehingga mampu menerima informasi tentang alat kontrasepsi yang diberikan melalui penyuluhan. Pengetahuan seseorang juga dapat dipengaruhi oleh adanya paparan media massa atau 
informasi (Notoatmodjo, 2007). Oleh karena itu, setelah wanita usia subur mampu menerima informasi berupa penyuluhan tentang alat kontrasepsi maka pengetahuan wanita usia subur tentang alat kontrasepsi meningkat. Perilaku yang diharapkan tidak terbatas pada peningkatan pengetahuan, namun menciptakan sikap yang positif terhadap pesan yang disampaikan. Hal ini sesuai dengan tujuan spesifik dari pendidikan kesehatan yaitu perubahan kognitif, perubahan motivasi dan perubahan perilaku (Notoadmojo, 2010). Berikut ini pelaksanaan kegiatan penyuluhan dapat dilihat pada Gambar 3 dan Gambar 4.

\section{KESIMPULAN}

Setelah mendapatkan penyuluhan dan pelatihan tentang alat kontrasepsi KB pada Wanita Usia Subur di Pendopo Dusun Dukuh desa Guwosari Kecamatan Pajangan Kabupaten Bantul, terjadi peningkatan pengetahuan tentang alat kontrasepsi KB. Peningkatan pengetahuan diketahui dari hasil pre test dan post test. Kenaikan nilai posttest sebesar $10 \%$ dibandingkan dengan nilai pretest sebelum dilakukan penyuluhan.

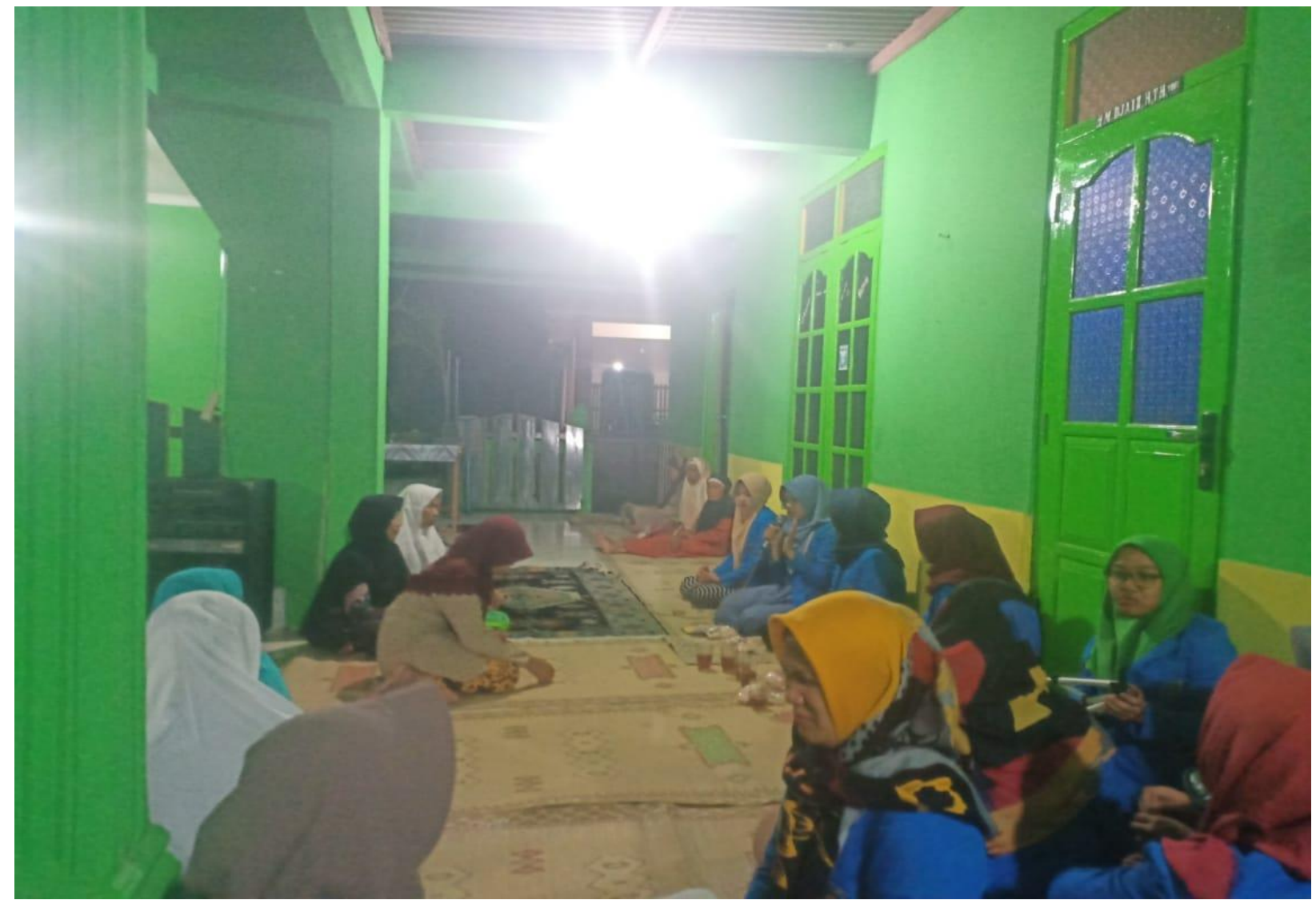

Gambar 3. Pelaksanaan Kegiatan Penyuluhan (1) 


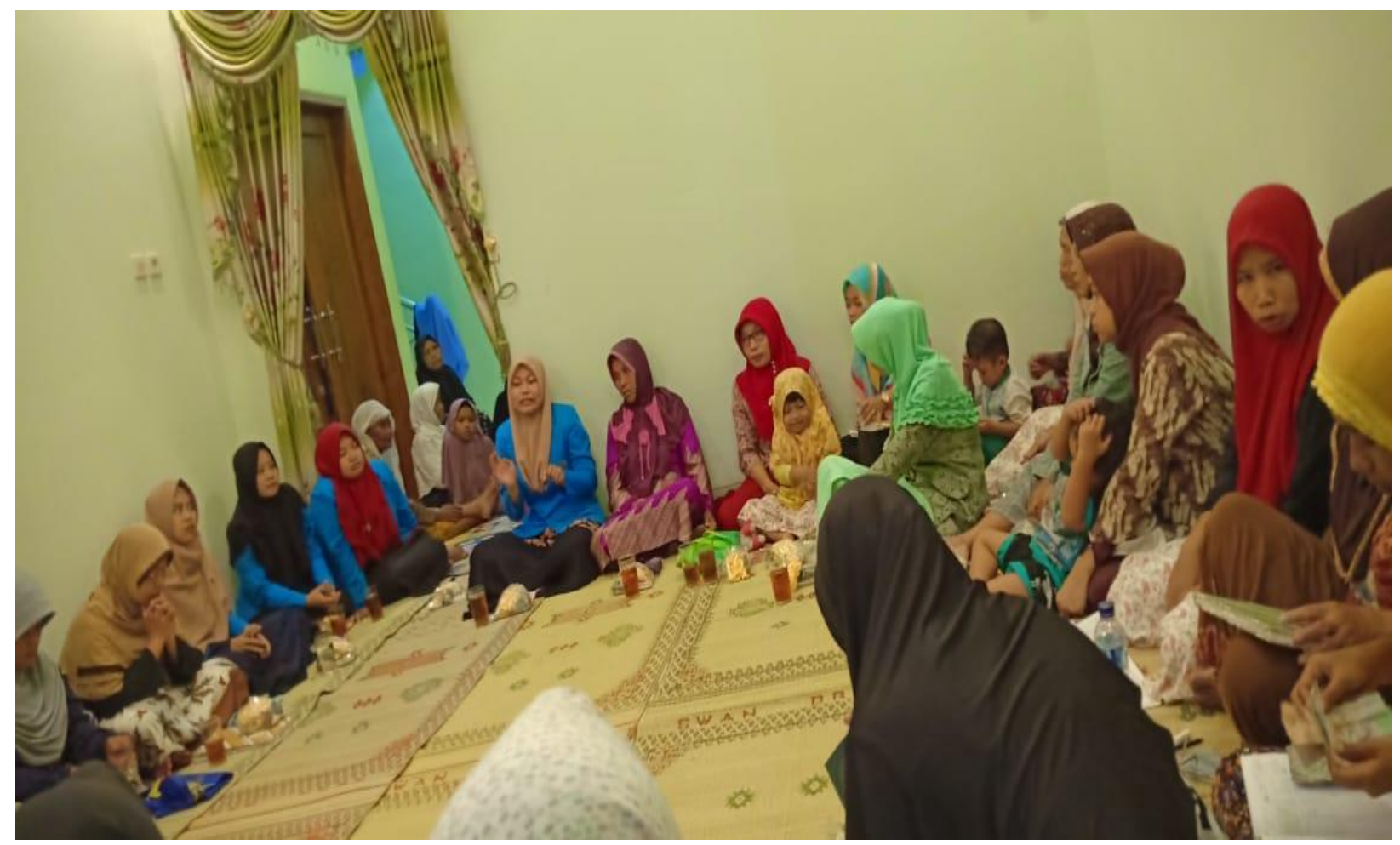

Gambar 3. Pelaksanaan Kegiatan Penyuluhan (2)

\section{REFERENSI}

Handayani, Sri. (2010). Buku Ajar Keluarga Berencana. Yogyakarta: Mustafa Rihama. Sulistyawati, Ari (2013). Pelayanan Keluarga Berencana. Salemba Medika:Jakarta. Notoadmodjo, S (2010). Ilmu perilaku kesehatan. Jakarta: Rineka Cipta.

Notoadmodjo, S. (2010). Promosi kesehatan teori dan aplikasi. Jakarta: Rineka Cipta.

Kaseuntung, C., (2015). Pengaruh penyuluhan kesehatan terhadap pengetahuan wanita usia subur (WUS) dalam pemilihan kontrasepsi di Desa Kalama darat kecamatan tamako kepulauan sangihe. e-journal keperrawatan e-Kp vol 3 no 3 agustus.

Syaifuddin., (2003). Buku Panduan Praktis Pelayanan Kontrasepsi. Jakarta : Yayasan Bina Pustaka Sarwono Prawirohardjo.

Hanafi H, (2010); Keluarga Berencana dan Kontrasepsi Edisi 7, Jakarta : Pustaka Sinar Harapan. Mubarak W.I., 2011. Promosi Kesehatan untuk Kebidanan. Jakarta: Salemba Medika Notoatmodjo, S., 2012. Promosi Kesehatan dan Perilaku Kesehatan. Jakarta: PT. Rineka Cipta 